\title{
Corporate Learning in Times of Digital Transformation: A Conceptual Framework and Service Portfolio for the Learning Function in Banking Organisations
}

\author{
http://dx.doi.org/10.3991/ijac.v8i1.4440 \\ D. Schuchmann and S. Seufert \\ University of St.Gallen, Switzerland
}

\begin{abstract}
Digital transformation is one of the major challenges in all industries. It embraces the realignment of technology and new business models to more effectively engage digital customers at every touchpoint in the costumer experience lifecycle. Therefore, successful digital transformation begins with an understanding of digital consumer behavior, preferences and choices. It then leads to major consumercentric changes within the organisation that address these needs. Such a consumer-centric and self-directed client structure has significant consequences for banks. Banks will need to continue existing services, while developing strategies to manage the shift in mix.
\end{abstract}

For that reason, banking organisations are challenged to consider exploration new business fields and not only focus on exploitation anymore. Finally they need to ensure a successful balance between both. This means they have to establish a general development orientation and afford implementing innovations at the same time they focus on efficiency by utilizing and optimizing the existing. Pressure for doing this is definitely there and causes in current dynamic changes in the finance market, new competitors in the branch and little differentiation among offered banking services. Hence, they need to enhance their continuous learning ability, which is an essential precondition for coping with innovations.

This paper follows the research question "how can the learning function foster the enhancement of the banking organisation's learning and innovation ability in times of digital transformation?" This is closely linked to the kind of services a learning function needs to enhance or integrate for supporting and designing a learning organization. With the idea underlying enterprise 2.0 , social media platforms offer valuable opportunities for doing this. From an educational management perspective, we focus on the design levels of individuals, teams, and organisation in banks.

Derived from our theoretical framework we suggest a conceptual model for managing organisational learning for continuous innovation based on four action areas. We examine the appropriateness of this framework in the practice field through eleven case studies in banking organisations. This approach allows a further development of these areas and to develop an understanding of what are current and future starting points for action in banking organisations. Finally, we identify new roles and services of the learning function for supporting the organisations.
Index Terms-digital transformation, enterprise 2.0, continuous innovation, corporate learning, learning function.

\section{INTRODUCTION}

Digital transformation challenges almost every industry nowadays. Retail banking is especially hard affected by the implications. Banks have to adjust their business models driven by the rapid adoption of technology that puts increasing power in the hands of every (digital) consumer resulting in higher demands. [1]. For instance, new finance communities (e.g. Wesabe, Prosper, Boober etc.) and banking models are emerging while information concerning the financial institutes is easily accessible. Thus, typical banking services, e.g. to grant credits, fund management or stock dealing, are already offered outside the finance organisations. Furthermore, customers are willing to change their financial service provider more quickly [2].

However, banks may not rest on past successes - they feel pressure to deal with this increasing and changing competition on the market. Taking a look into the future, banks need to develop new or extended business areas as well as management innovations. Constantly searching for new business models is essential [3], which go far beyond traditional banking services. For the organisation's capability to be innovative and to focus on a developmentorientation in general, continuous learning is the most important precondition [4]. "Speed competition in regard to build up new core competencies, new skills, which lead to sustainable advantage in competition ..., mean competition in the area of the ability to learn and change at last" [1]. Ultimately, the organisation's continuous learning is the essential precondition for its capability to be innovative [5].

The enormous relevance of the organisations' development capability also requires fostering the employees' self-organisation for learning as well as for working terms which claims for an implementation of new organisational forms, leadership modes and management systems [6], [7]. This points out a high importance of interlinking the employees' learning to the organisation's development. Both can be enabled through the institutionalisation of learning- and development-oriented structures and cultures. Besides, some authors have already emphasized that managers take an extremely important role by addressing 
those requirements - they need to act as learning facilitator [8], [9].

Moreover, the outlined situation holds the challenge for banking organisations to deal with ambidexterity [10], [11], [12]: a concentration on efficiency is fundamental by using the existing and optimizing synergy effects (exploitation). At the same time, this demands for pursuing a continuous improvement through a learning orientation and capability for change, a proactive acting and an ability to deal with trends and developments. This demands very early recognition, evaluation, and preparation, which means being able to exploit the new and to develop different types of innovations at last.

Especially banking organisations possess unique organisational frame conditions implying structural and/ or cultural barriers for acting in the sense of a learning organisation; managers and employees are rarely used to act in an uncertain environment. Therefore, the organisation's capability of learning and development needs to be considered as starting point to enhance the ability for innovation.

Until now, no systematic approach in the banking context exists. Only a few publications and investigations focus on selective aspects in the banking context, e.g. [2], [13], [14], [15]. Against this, some theoretical approaches and considerations in regards to connected scientific discussions like ambidexterity, e.g. [10], [11], [12], [16], organisational learning, e.g. [17], [18], [19], or knowledge management [20], [21], [22], [23], [24], [25], [26], in organisations are available. Those are involved in our theoretical foundations.

This paper aims to contribute address this gap, so that valuable implications on theory and practice can be delivered through delivering empirical evidence from the banking sector. Hence, we follow the research question "how can the learning function foster the enhancement of the banking organisation's learning and innovation ability in times of digital transformation?" Moreover, we want to identify how the learning function (we understand this as containing all activities to enable and organize learning inside an organisation - thus, the learning function could be an internal or external one) can support banking organisations in enhancing their learning and development capability in the sense of a learning organisation.

First of all, we outline the theoretical foundations of this research project in a holistic approach with a focus on four levels in the organisation. Relevant discussion threads like organizational learning, organizational ambidexterity, knowledge management and enterprise 2.0 are contained. In a second step, we introduce a conceptual framework for managing organisational learning with the objective to enhance the ability for learning and development of the organisation. This framework is based on four action areas and the close connection between personnel and organizational development. This concept derived from the theoretical foundations described previously.

We validated and adapted this framework through qualitative case study research and thus gained empirical evidence from banking organisations. Our methodical approach is described in chapter 3. Afterwards, central results are outlined in chapter 4.

In chapter 5 we conclude and discuss essential findings and illustrate starting points for future research.

\section{THEORETICAL FOUNDATION}

\section{A. Organisational Capability for Learning and} Innovation - a Holistic Approach

A few authors understand the corporate's capability for learning connected to its capability for coping with ambidexterity. For instance, reference [12] define ambidexterity as "a deliberate approach to variation-selectionretention that uses existing firm assets and capabilities and reconfigures them to address new opportunities. When done explicitly, this involves deliberate investments and promotes organisational learning that results in a repeatable process [27], [28]. This is a dynamic capability that has been characterized as the firm's ability 'to learn how to learn' and can be used to promote exploration and exploitation". In the following, we mainly concentrate on exploration, because banks are newly required to meet the challenge to implement exploration from scratch - in an addition to exploitation (nonetheless, we emphasize that both modes need to be established in the organisation equally).

The organisation's ability to learn is an essential precondition for the ability to innovate, because it fosters the capacity to develop and adapt to environmental changes. Learning and innovations are interlinked as follows: "An organisation is not only able to learn, irrespective of purpose, but also ultimately learns if innovations or an innovative solution to problems is created as a result" [9]. Also reference [29] see the close relationship between learning and innovations in the challenge "that new, situative and creative solutions for a particular set of problems have to be found or created. The ability to innovate depends to a large extent on the ability to think up and implement new ideas and to reflect on previous experiences and, not least, to be able to draw well-founded conclusions; factors which favour organisational learning are also central in the capacity to innovate". This already points out that the individual members of an organisation need extensive competencies for their ability to learn and innovate. Obtaining such competence is aligned to both processes of individual's competence development and innovation processes in the organisation.

Based on these considerations, innovation ability implies requirements in the following two dimensions [7]:

- individuals are required to learn continuously and reflexive in their daily working processes,

- the organisation needs to enable and implement innovations through designing frame conditions.

Providing learning- and innovation-oriented frame conditions involve designing an adequate strategy, structures and cultures which possess the assumption that "without experimentation and being able to learn from mistakes, i.e. putting a distinctive error and critical culture into practice, to reflect upon experience, question basic norms and supposed certainties and to think creatively, innovations can hardly be produced. This applies in the same way to both the organisational and individual levels" [29]. Table 1 shows four levels of organisational learning by taking up these considerations: the levels of individual learning, team learning and organisational learning are fundamental for the organisation's ability to innovative and for "the innovative resolution of problems" [9]. In this sense, the interlocking between personnel and organisational development is fundamental: innovation capacity is "in- 
separable ... from competent persons and flexible companies. Personnel, organisational and competence development thus stand side by side with equal worth in an integrated innovation management system." [5].

As the table already shows, knowledge is another very relevant topic area in the context of corporate learning. From an educational management perspective, an "organisational knowledge base" is a basic term [26]. This base describes the whole knowledge inside the organisation merged, which is available and made accessible at the organizational level. So it depends on "which knowledge of all individuals is available and which knowledge is accessible to the individuals" [38]. Hence, individual as well as collective knowledge influences the base. For the facilitation of a learning organisation, the following processes for knowledge management need to be considered: generation, distribution, conservation and utilization of information and knowledge [39].

In the understanding of enterprise 2.0 (E2.0), web 2.0 tools contain new opportunities to cope with these knowledge management processes in collaborative ways. Thus, such tools can be implemented to support flows of knowledge and information in a way that facilitates learning. Enterprise 2.0 implies also consequences or even preconditions in new organisation logic: restrictions for predefined working processes, roles or responsibilities were not imposed - they allow arising by itself. This means that employees are required to "create and refine content - even without or little conditions. Users produce content themselves ('user generated content'). Producing and sharing of knowledge with others is voluntary, extensively spontaneous and decentralized, interactive and collaborative." [3]. For instance, reference [21] sees E2.0 as ,the dawn of emergent collaboration”, where responsibility for content and its quality is distributed "to all members and the flow of knowledge carries various directions" [26]. Web 2.0 tools can follow the objective to "support collaboration, improve access to knowledge and expertise, enhance productivity and professional capability of teams, improve networking with customers, partners and the expanded environment, enhance the agility and innovation capability" [3]. Finally, informal and self-organised learning can meet the requirements for workplace-integrated learning.

\section{B. Managing Organisational Learning - \\ A Conceptual Framwork}

Based on the briefly outlined theoretical foundations, we developed a conceptual framework [3] for managing organisational learning aiming to enhance the ability for continuous learning and innovation in organisations (cf. Figure 1). In this framework, the levels of individual, team and organisational learning are integrated. Additionally, the requirement to closely connect personnel respectively human resource development (HRD) and organisational development (OD) were met.

This framework describes four main action areas inside the organisation to enhance the ability for learning and development:

Personnel development as executive management task: since the competence-oriented reversal of personnel development, the focus is on employee's self-organisation and their competence development. This requires new development concepts, which also consider developing
TABLE I.

FOUR LEVELS OF ORGANISATIONAL LEARNING (PAPER EURAM 14?)

\begin{tabular}{|c|l|}
\hline Global Level & $\begin{array}{l}\text { - Connect the organization to its environment } \\
\text { - Motivate actors to share the same vision }\end{array}$ \\
\hline $\begin{array}{c}\text { Organization- } \\
\text { al Level }\end{array}$ & $\begin{array}{l}\text { - Ensure to take learning impulses into account } \\
\text { - Ensure to generate, use and share knowledge }\end{array}$ \\
\hline Team Level & - Afford collaboration and "learning to learn" \\
\hline $\begin{array}{c}\text { Individual } \\
\text { Level }\end{array}$ & $\begin{array}{l}\text { - encourage the actors for trial, asking questions } \\
\text { and discussions }\end{array}$ \\
& $\begin{array}{l}\text { - afford continuous learning (create learning } \\
\text { infrastructures and appropriate working condi- } \\
\text { tions) } \\
\end{array}$ \\
& foster employees' instrinsic motivation \\
\hline
\end{tabular}

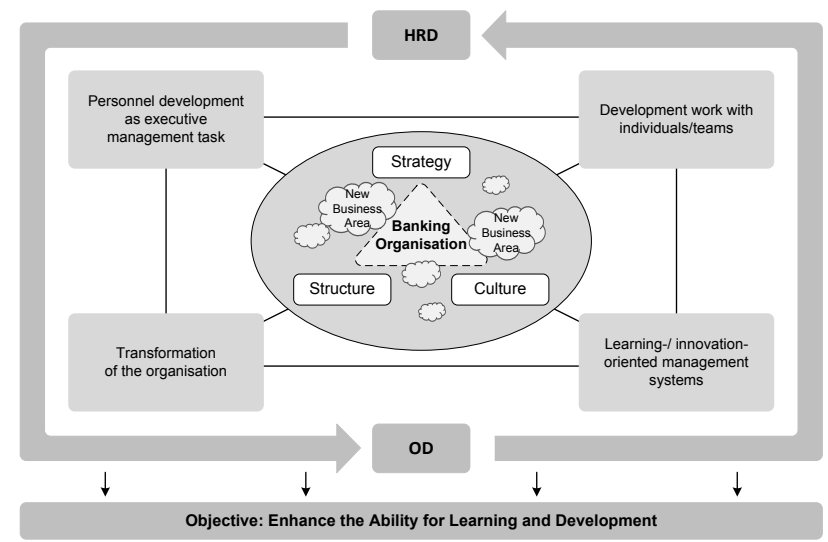

Figure 1. Conceptual framework -

four action areas for a learning banking organisation [3]

competencies in informal learning processes and thus workplace-integrated learning.

This leads to a decentralization of personnel development tasks into working processes; managers need to engage in an extended role as learning facilitator and pedagogical-didactical tasks in the workplace. A precondition is an "appropriate understanding of leadership is fundamental as well as their willingness to take up this new and extended role" [3]. Furthermore, managers are fundamentally responsible for providing frame conditions for learning and knowledge generating and sharing.

Development work with individuals/teams: the previous field already indicated that new learning and networking forms are increasingly important. Essential is to connect informal and formal learning, e.g. through developing real and effective learning environments at the workplace. Also, new working forms could be designed to foster knowledge sharing and enable learning processes (e.g. project teams for generation of new ideas across hierarchies). In general, the employees' collaboration is essential. These learning and working environments demand for new competencies of the employees to be able to act successfully in these new and changing environments. "When designing such new learning forms, didactical and management-oriented organisation of learning needs to be adjusted." [3].

Besides an internal dimension, these delineations also have an external dimension: on the one hand this is about internal knowledge acquiring and sharing, on the other hand employees should involve and access to knowledge outside the organisation to continuously expand the organizational knowledge basis (e.g. in communication with customers). 
Transformation of the organisation: fundamental frame conditions for learning at all levels are given through the organisational strategy, structures and especially cultures. These conditions respectively preconditions for learning need to be designed in deliberation. Finally, banks have to transform into this direction to be able to deal with knowledge and innovations.

Learning/innovation-oriented management systems: the evaluation of the status of a learning-oriented organisation gets possible through learning- and developmentoriented instruments; these need to be newly designed and implemented. Therewith, this should consider the previous action fields as well as interlinkage of employees' development (HRD) and organisational development (OD). Regularly evaluations enable early interventions to correct the strategical direction in time.

Additionally, individual and collaborative opportunities for acting inside the bank are based on strategy, structures and cultures - all of them provide important frame conditions for the development capability:

Structures: the capability to adapt and change should be enabled e.g. through individual working arrangements and enabling learning [30]. This involves hierarchies, centralisation of decisions or development and career pathways.

Cultures: normative orientation inside the organisation is given through implicit rule, behaviour and value systems. Those are cultural frame conditions, which can either support or restrain learning [29].

Strategy: the vision of a learning organisation must be anchored in the strategy as this can be seen as development concept. This involves adding the continuous innovation-oriented mode to existing optimization orientation.

\section{METHOD}

The qualitative case study method was chosen to acquire empirical evidence for answering the research question "how can the learning function foster the enhancement of the banking organisation's learning and innovation ability in a digital world?". This methodical approach allows an in-depth examination of the current status in banking organisations in regards to their corporate learning approach as well as future initial points for action in a further development perspective [31], [32], [33]. The research and data collection process was divided into two sections:

In a first step, we involved three banking organisations in Germany which possess specific approaches to address current challenges in their environment. Here, in-depth interviews were conducted with various persons in different positions in the time frame from February to March 2014 (board chairmen, managing directors, department heads for company development). Partially-structured guiding questions were the basis for these interviews [34], [35]. These were developed based on results of an extensive literature analysis. Even though the guiding questions enabled data collection in relative openness and flexibility and setting individual and various particular focuses, opportunities to compare the data among the three cases were ensured through selective standardized inquiries. During the process, there was a focus set on the following three topic areas:

- current challenges posed to banks and understanding of a "bank organisation capable of development",
- feedback and discussion of the previously developed conceptual framework and the outlined four action areas,

- possible roles and services of an (external or internal) learning function aiming to support the banks in enhancing their learning and development ability.

The three cases were chosen through theoretical sampling criteria: the banking organisation should possess innovative approaches to promote a development-oriented organisation. This enabled the identification of success factors for development-capable banks. Table II delineates an overview of the cases considered.

TABLE II.

CASES OVERVIEW

\begin{tabular}{|l|l|c|c|}
\hline & Focus topic of the bank & Locations & $\begin{array}{c}\text { Employees } \\
\text { in total }\end{array}$ \\
\hline Case 1 & $\begin{array}{l}\text { Managing continuous changes } \\
\text { through employees' involvement } \\
\text { and quality-oriented processes }\end{array}$ & 35 & 420 \\
\hline Case 2 & $\begin{array}{l}\text { Digital transformation of the bank- } \\
\text { ing organisation }\end{array}$ & 28 & 307 \\
\hline Case 3 & $\begin{array}{l}\text { Value-oriented leadership to } \\
\text { achieve high performers }\end{array}$ & 11 & $150-160$ \\
\hline
\end{tabular}

The particular thematic focuses for the individual banking organisations was to be varied in order to integrate a broad range of approaches. Also, banks of different sizes were involved in order to examine the varying framework conditions in each case. The evaluation of these first three case studies took place via single-case-analyses.

In a second step, further "smaller" case studies were conducted through interviews in eight other banking organisations in Germany. Data was collected in the period from May to July 2014. This followed the objective to check the previously gained results across the board and adapt them if necessary. In contrast to the first data collection step, "typical" banks were involved here; that means established innovative approaches were not an indispensable selection criterion. Instead, banks were selected by random. The partially standardized questionnaires used in the previous in-depth case studies were heavily abridged, retaining central aspects involved and used as the basis for the interviews. Besides, the selective standardized inquiries retained, so that these data could have been consolidated with the data of the three previous cases and lead to a "broad" picture. The last step was a cross-case analysis [32], which allowed comparing the results of every single case and identifying and developing general findings.

\section{RESUlTS}

\section{A. Action Areas for Enhancing Corporate Learning}

All interview partners respectively bank representatives were asked to assess the four action areas in the following regards:

- Which field is the most important for improving the development capacity of the bank?

- How do you evaluate the effect of each area in your bank? (6-point Likert scale: low (1) - high (6))

- How do you assess the feasibility, i.e. design potential (6-point Likert scale: easy (6) - difficult (1)).

- The close connection and interrelation among all fields was highly emphasized by the results. 
TABLE III.

RESULTS: ASSESSED EFFECT AND FEASIBILITY OF ACTION AREAS

\begin{tabular}{|l|c|c|}
\hline & Effect & Feasibility \\
\hline PD as executive management task & 5.39 & 3.80 \\
\hline $\begin{array}{l}\text { Development work with individuals/ } \\
\text { teams }\end{array}$ & 4.60 & 4.35 \\
\hline Transformation of the organisation & 4.61 & 4.09 \\
\hline $\begin{array}{l}\text { Development of learning/innovation- } \\
\text { oriented management systems }\end{array}$ & 4.59 & 3.90 \\
\hline
\end{tabular}

The action area "personnel development as executive management task" was evaluated the highest effect with simultaneously the least feasibility. In regards to feasibility, all action areas are assessed in the positive respectively feasible zone (values above 3.5). Moreover, the action field "development of learning/innovation-oriented management systems" is rated as the second most difficult field in terms of implementation.

With these results, excellent starting points for the learning function can be pinpointed: Although all fields are considered as relevant, clearly on top is "PD as an executive management task". Nevertheless, this area can also be used as a lever for other fields, because all fields are closely interrelated and constitute an impact network. The fact that this area is assessed in the forefront also indicates an "oft-cited prior change in executive management of bank practice" [36]. Some central results are summarized in the following.

PD as executive management task: In all banks the understanding of personnel development as leadership task is already strongly anchored and seen as essential for successfully implementing values and norms in the organisation ("living out values"). Thus, executive management seems to be ready to assume this extended role. However, especially in terms of recognition of potentials and support individual employees, the existing competencies are currently considered to be insufficient (e.g. case 3 ). This identifies an initial point for developing executive management appropriately. Besides, it is a fact that manager's potential for supporting the development of employees does not always exist (e.g. case 2). This is caused in the promotion of managers based on others than leadership competencies.

A further starting point for the learning function is the initiation and facilitation of knowledge transfer and experiences sharing among managers with regards to leadership questions - structured processes are required in all cases. For instance, the creation of knowledge networks has been suggested ("everyone has similar problems") as well as collegial consultation. Additionally, the managers need protected "spaces for reflection" for their development and without the hazard to lose face. This could be provided by the learning function. Also mentioned were systematic coaching processes or on-the-job training as valuable elements in the executive development. The learning function could also take a consultative role with the objective of "bringing the entire bank forward at the organisational level would thus also be conceivable" [36].

Development work with individuals/teams: In general, structures in the organisation should permit "work forms with innovative character", while the "classic functions" should remain in place. This highlights the need of to establish project structures in parallel. Again, the learning function could offer support here.
Even though banks have already tested and used new learning forms (e.g. pass system as well as on-the-job coaching and training) in some cases, most of the established learning forms are declared to be too rigid and learning content and purposes are set in top-down manner (e.g. case 1). Therefore, more self-organised development work with individuals and groups is an action field in future. In this context, collaboration between and discussion among employees is considered very important. "Employees need to learn to work together in processes, which is emphasised in the sense of team learning. An interest-driven group composition is important in particular for subjects linked to change (e.g. knowledge, development and project groups). The goal is to have knowledge shared and used by as many employees in the entire bank as possible." [36]. This could be supported through an appropriate technical exchange and collaboration platform. Developing, providing and moderating such a platform and communities (web 2.0 solutions) is recognised as tasks for the learning function.

Besides, webinars on relevant subjects are a favoured learning format. Banks would use them more often if they were made more easily accessible by being offered by the (external) learning function.

In situations, when new career and development paths are demanded by the market due to developments (e.g. new types of consultant are needed in case 1), the learning function should react rapidly in creating these paths and thus support the banks. Similarly, the offer of project careers as well as executive careers was proposed. Partially, working on individual projects has already been made possible, but this could be expanded further.

Transformation of the organisation: For an active design of this action field, the readiness and will of board members are essential preconditions. They act as central (power) brokers when it comes to having new subjects addressed by the bank. If the learning function takes the role to initiate organisational transformation by focusing on new subjects, it should sensitise the board members step-by-step. Additionally, further managers need to act as "visionaries" to promote such subjects - "driving forces" are needed; the bank needs to have the "right employees", especially when the transformation requires cultural changes. Board members necessarily need external support to get ideas for structured processes and support in implementing them. At the same time, it must be ensured that managers (can) actually implement what is learned the transfer should be accompanied in a transfer-oriented learning design.

Activities in this field need to be seen as "ever-present tasks that have to be continually initiated anew" [36]. This means for the learning function that these subjects have to be constantly re-injected into existing offers (that are already considered to be quite relevant and are thus well attended). Furthermore, the interview partners highlighted that they need "to be able to work on subjects/content itself", which should be supported by the learning function in a results-oriented moderator role and to provide methods and formats. Furthermore, a bank can be supported in opening established structures through "informal structures outside of the structures" in which new rules can be applied.

Another relevant topic in this field is knowledge management: it is seen important to acquire new external 
knowledge from outside the organisation and also to share knowledge inside the bank, which is connected to establishing incentive systems for doing this. Also, in all cases there is no idea how to share/ distribute knowledge in a structured way; the learning function could supply these ideas and appropriate instruments.

Affording voluntary and interest-driven collaboration in (informal) groups, especially on development topics is also significant here (e.g. case 2). This includes bringing persons together so that they can jointly develop solutions - on an employee as well as on a manager's level across various banks. Solutions could then be specified for the individual banks in a next step.

Technical or social media platforms are perceived as important for the future, because they can foster the implementation of previously outlined considerations. At the same time, this is seen difficult to implement. In a first step such a platform could be used internally, and later also externally. Engaging in the general discussion in banks whether to use such platforms or not, or integrating such current topics in existing learning offers already shows a starting point for the learning function and could result in overcoming the "don't know it" barrier. The identification, possible applications and their implementation, the development and provision of social media platforms (use within a bank and across banks) is a further starting point for the learning function. Here, the professional operation (including moderation) is a precondition for use (case 3). External expertise would also be valuable for.

Generally, the communication is an essentially relevant topic for its transformation in both dimensions: internal ("the more transparent and open communication is, the quicker and more effective the transformation.") and external in terms of the exchange with other banks and the client-bank relationship. The last mentioned integrates clients/members in communication paths and collaboration processes (e.g. through feedback). The relationship with clients and thus advisory services continue to be a focus of banks - distinguishing features are to be created here.

Development of learning/ innovation-oriented management systems: All interview partners see a wide range of instruments available. Thus, it would not be valuable to add more instruments to them. Especially the Balanced Scorecard (BSC) was mentioned as a useful instrument to measure the impact of changes in the organisation. Indeed, the impact of the existing instruments was partially questioned. This is reasoned in the fact that appropriate measures to not lead into consequences in practice. Hence, a linkage between management systems and the topic of the organisational's transformation should be ensured. This also means to reconsider and clearly define what should be measured at all. Besides, a demand for measuring the effects of investments in education on the organisation was figured out. This would involve a focus on the transmission of knowledge and the quality of this knowledge.

All in all, evaluation instruments should focus on the level of the banking organisation and not only on aspects of the individual levels.

Finally, the learning function should also support and facilitate the exchange between persons/groups/banks who want to act in a similar (innovative) way, and thus are interest-driven. This implies the maintenance of networks among banks, which are currently assessed differently in the banks. A starting point could possibly be activities for supporting benchmarking or best practice sharing. In addition, a branch opening would enable to learn from other companies.

\section{B. Service Portfolio of the Learning Function in Times of Digital Transformation}

With these results it can be pointed out that there are already many developments going on in the banking organisations towards the implementation of web 2.0 tools to facilitate learning and promote sharing of knowledge, experiences and ideas. According to that, learning is moving away from formal into informal learning contexts: away from traditional classroom learning towards selforganised workplace learning in collaboration. This means for the learning function that facilitation, organisation and management of learning needs to be supported in new roles and services.

A previously developed continuum model which visualizes four types of logic for the organisation of learning processes [37] from standardized trainings (in formal contexts) towards self-initiated communities (in informal contexts) (c.f. Figure 2), gives an appropriate framework to illustrate the new services of the learning function. The types of logic for organizing learning imply specific "learning services" as well as "development services" if the organisational development is an objective and thus needs to be linked to the learning of individuals. Here, the idea of designing framework conditions at organisational level is also considered. Furthermore, on the one hand the learning function needs to collaborate more closely with "partners", especially managers and employees to enable such new learning formats; on the other hand all partners (including the learning function) take new responsibilities in each type of logic as well as for quality management. In summary, the learning services contain:

Training Services: the learning function takes responsibility for design and implementation of trainings as well as for quality management; the trainings take place in a formalized context like classroom learning. The relevance of this type is decreasing.

Transfer Support Services: the learning function is still responsible for design, implementation and quality of educational programmes and initiates learning activities. Here, managers are already involved in learning processes. They take a transfer supporter role at the workplace, e.g. through aligning goals with employees, coaching or mentoring. Ideally, they work in close collaboration with the learning function.

Performance Support Service: now, the manager takes the leading role as moderator in learning activities and employees' self-organisation becomes significant. Both take responsibility for the quality of learning. Learning processes were initiated in working processes, whereat, for instance, employees can immediately get access to performance supporting learning material like videocasts, wikis, or find experts. The learning function supports the managers if required.

Services for Collaboration in Working Processes \& Networks (internal/external): employees take the leading role and responsibility for their learning activities; selforganisation is fundamental. Managers need to design 


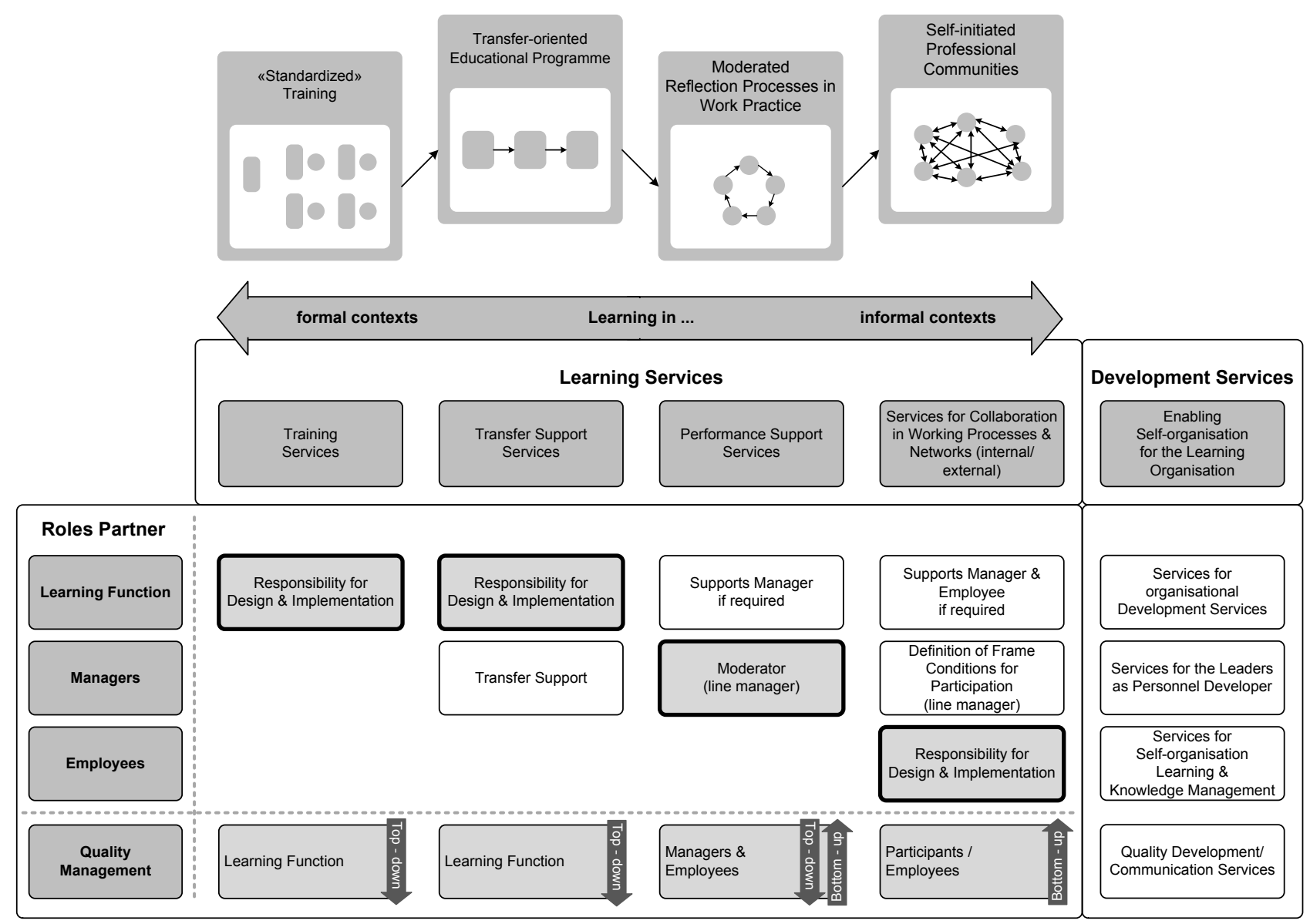

Figure 2. Service Portfolio of the Learning Function [36]

(organisational) frame conditions (e.g. to provide time, opportunities, support). The learning function supports both, managers and employees. Here, tools or social media platforms for collaboration or networking are allocated.

Development Services for the Learning Organisation: the objective here is to support the organizational transformation to move away from purely formal trainings to enable the more informal learning types and selforganisation, e.g. communication services or services for "agenda-setting". This possesses an internal and external dimension. Internally, this means developing employees' competencies they need for acting in new learning and working environments. Also, managers need to be supported in their extended role as personnel developer.

\section{DISCUSSION AND CONCLUSION}

To answer the research question "how can the learning function foster the enhancement of the banking organisation's learning and innovation ability in times of digital transformation?", we validated and modified the conceptual framework through case studies (11 in total), which was developed through an extensive literature analysis. The case studies confirmed the high innovation pressure they have to face. Also, the results gave a precisely understanding of the status of banking organisations in regard of what they already do to enhance their ability for learning and innovation; this enabled to identify current and future starting points for the (internal or external) learning function's support. Strength and validity of this work is given through combining the investigation of three in-depth case studies and eight "smaller" case studies for testing and modifying the results in a broad view.

We identified learning services and also new respectively changed roles and tasks of managers, employees and the learning function. This brings new challenges to all involved persons in taking these roles and responsibilities. Finally, the banking organisation needs to be fostered in its transformation towards a self-organised learning organisation. This is clearly linked to providing appropriate frame conditions like cultures and structures. These considerations demand for a movement away from a traditional seminar business; the service portfolio model thus implies a methodical perspective which considers the program portfolio of the learning function.

Successful digital transformation means that banks will need to continue existing services, while developing strategies to manage the shift in mix (e.g. support more selfdirected clients). Therefore, it is a similar challenge for the learning function to carefully provide a balanced mix supporting the shift to more self-organisation.

For a general coping with innovations, i.e. evaluation of trends and management innovations, the establishment of an external or cross-bank knowledge/ ideas/ experience exchange system would permit rapid reaction and review to emerging subjects. Besides and in an internal perspective, the employees' involvement in development and change processes is considered to be highly important and is partially implemented through various approaches in all cases. This involvement leads to a better use of ex- 
isting knowledge and individual experiences in the organisation. Figure 3 shows the different levels for the transfer of knowledge, which should be considered here:

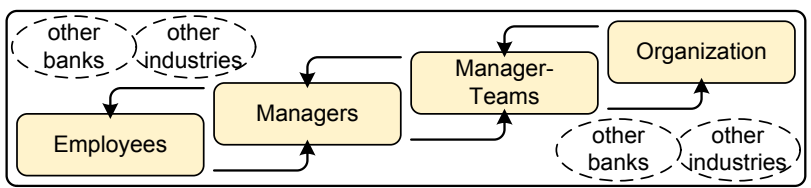

Figure 3. Internal and external levels for knowledge transfer [37]

The case studies also emphasized a new approach for further developing products and internal development processes: it is no longer seen sufficient to undergo long development processes with a flawless product or service in result. We found increasing acceptance of a permanent test mode respectively "beta versions" in the banks which lead to products/services that are not entirely mature and need to be further developed together with clients in order to gather experience, test them and not waste any time in the process. This is connected with considering failure as learning opportunity and accepting both, success and failure.

Above all, employees have to be appropriately developed and a general readiness to change needs to be established; change should represent a usual work mode. This requires the employees' ability to change. Managers must therefore be developed accordingly so that they can support these change processes. Finally, it can be stated that competencies need to be developed for enhancing the organizational ability for learning primarily in two dimensions - they offer starting points for the learning function:

- Competence development of managers: functional qualification, value-oriented leadership, focus on long-term success, talent development and recognition, etc.

- Competence development of the organisation: extension of business areas, strengthen selforganisation, promote a culture of participation with employees and customers, support coping with changes, etc.

These considerations can be understood as competence model for a learning bank with managers taking an important role. Thus, these dimensions describe a normative perspective - for the organisation as well as for the learning function.

All in all, we were successful in identifying many valuable initial points the learning function to support banks in their transformation towards a self-organised learning organisation to enhance the ability for innovations. Future research should then focus on developing a program portfolio including appropriate specific services. This is connected to specific methodical terms as well as to the question how the identified starting points in each action area can be successfully implemented and facilitated through the learning function in their services. According to the results, the action field "personnel development as an executive management task" should be addressed in a first step. Here, the advantages of its important lever effects on the other actions areas have to be deliberated.

\section{REFERENCES}

[1] J. Rüegg-Stürm, "Entwicklung und Messbarkeit von Wandelfähigkeit: Stolpersteine und Perspektiven der Lernenden Organisation," in Wie die Verwaltung lernt. Der öffentliche Sektor auf dem
Weg zur lernenden Organisation, Eidgenössisches Personalamt, Ed. Bern: Eidgenössische Drucksachen- und Materialzentrale, 1998, p. 239-262.

[2] D. Stoller-Schai, "Lernen 2.0 in der Finanzbranche," in Personalentwicklung 2.0, 1st ed., T. Jenewein and A. Trost, Eds. Köln: Hermann Luchterhand, 2011, p. 109-129.

[3] D. Schuchmann and S. Seufert, "The changing Service Portfolio of the Learning Function to design Learning Organisations in the Digital Age: Evidence from the Banking Industry." European Academy of Management, Valencia, 2014.

[4] M. A. Weissenberger-Eibl, Innovationen und Lernen, Presentation at the F.PAK Kolloquium, München.

[5] M. Haarich, S. Sparschuh, C. Zettel and F. Hees, "Innovationsfähigkeit - Lernfähigkeit - Transferfähigkeit: Innovationen systematisch fördern," in Enabling Innovation. Innovationsfähigkeit deutsche und internationale Perspektiven, S. Jeschke, I. Isenhardt, F. Hees and S. Trantow, Eds. Berlin, Heidelberg: Springer, 2011, p. $447-464$.

[6] R. Wunderer, Führung und Zusammenarbeit. Eine unternehmerische Führungslehre, 5th ed., Köln, München: Luchterhand, 2003.

[7] M. Lang and G. Pätzold, "Neue Wege zum Erwerb von Arbeitsprozesswissen in hoch automatisierten Produktionsprozessen der Chemischen Industrie - Die Aneignung netzbasierter Lernumgebungen zur Verknüpfung von formellem und informellem Lernen im Arbeitsprozess." in Innovationen und Tendenzen der betrieblichen Berufsbildung, P. Dehnbostel and G. Pätzold, Eds. Stuttgart: Steiner, 2004, p. 97-106.

[8] S. Gibb, "Line manager involvement in learning and development: Small beer or big deal?" Employee Relations, 2003. 25(3): p. 281293. http://dx.doi.org/10.1108/01425450310475865

[9] S. Seufert, Bildungsmanagement. Einführung für Studium und Praxis, Stuttgart: Schäffer-Poeschel, 2013.

[10] J. G. March, "Exploration and exploitation in organizational learning," Organization Science, 1991. 2: p. 71-87. http://dx.doi.org/10.1287/orsc.2.1.71

[11] C. Gibson and J. Birkinshaw, "The antecedents, consequences, and mediating role of organizational ambidexterity," Academy of Management Journal, 2004. 47: p. 209-226. http://dx.doi.org/10.2307/20159573

[12] III O'Reilly, C. A. and M. L. Tushman, "Ambidexterity as a dynamic capability: Resolving the innovator's dilemma." Research in Organizational Behavior, 2008. 28: p. 185-206. http://dx.doi.org/10.1016/j.riob.2008.06.002

[13] P. Seibold, "Noch Platz für Organisatoren in der lernenden Bank?" in Die lernende Bankorganisation. Strategien für die Jahrtausendwende, Congena, Ed. Wiesbaden: Gabler, 1995, p. 193-204.

[14] Deutsche Bank AG, Fraunhofer IAO, Wettbewerbsfaktor Wissen: Leitfaden zum Wissensmanagement, Frankfurt am Main: Deutsche Bank, 1999.

[15] N. Köpff, Wissensmanagement und Handbücher im Finanzsektor: Ein Wiki mit Blog für die Kreissparkasse Saalfeld-Rudolstadt, 2012. http://blog.hallowelt.biz/2012/12/10/wissensmanagementund-handbucher-im-finanzsektor-ein-wiki-mit-blog-fur-diekreissparkasse-saalfeld-rudolstadt/

[16] K. M. Eisenhardt and J. A. Martin, "Dynamic capabilities: What are they?" Strategic Management Journal, 2000. 21: p. 1105$1121 . \quad$ http://dx.doi.org/10.1002/1097 0266(200010/11)21:10/11<1105::AID-SMJ133>3.0.CO;2-E

[17] P. M. Senge, Die fünfte Disziplin, Stuttgart: Klett-Cotta, 1996.

[18] C. Argyris and D. A. Schön, Die lernende Organisation. Grundlagen, Methode, Praxis. Stuttgart: Klett-Cotta, 1999.

[19] U. Wilkesmann, Lernen in Organisationen. Die Inszenierung von kollektiven Lernprozessen, Frankfurt am Main: Campus, 1999.

[20] H.-J. Bullinger, J. Prieto and K. Wörner, Wissensmanagement heute: Daten, Fakten, Trends. Fraunhofer-Institut für Arbeitswirtschaft und Organisation (IAO), 1997.

[21] A. P. McAfee, "Enterprise 2.0: The Dawn of Emergent Collaboration," MITSloan Management Review, 2006. 47(3): 21-28.

[22] T. Davenport, Enterprise 2.0: The New, New Knowledge Management? HBR Blog Network, 2008. http://blogs.hbr.org/2008/02/enterprise-20-the-new-new-know/ 
[23] M. Göhring, "Banken und Kommunikation 2.0," in Innovationen und Konzepte für die Bank der Zukunft. Mit modernen Vertriebslösungen und optimierten Wertschöpfungsprozessen künftigen Herausforderungen begegnen, D. Spath, W. Bauer and M. Engstler, Eds. Wiesbaden: Gabler, 2008, p. 161-167.

[24] A. Stobbe, "Enterprise 2.0 - Wie Unternehmen das Web 2.0 für sich nutzen. Deutsche Bank Research," Economics, 2010. 78: p. $1-16$.

[25] M. Koch, A. Richter and A. Stocker, Enterprise 2.0 - Wissensmanagement der neuen Generation?, 2012. http://www.soziotech.org/enterprise-2-0-wissensmanagement-derneuen-generation/

[26] G. Probst, S. Raub and K. Romhardt, Wissen managen. Wie Unternehmen ihre wertvollste Ressource optimal nutzen, 7th ed. Wiesbaden: Gabler, 2012.

[27] S. Ethiraj, P. Kale, M. S. Krishnan and J. Singh, "Where do capabilities come from and how do they matter: A study in the software services industry," Strategic Management Journal, 2005. 26: p. 25-45. http://dx.doi.org/10.1002/smj.433

[28] J. B. Harreld, III O’Reilly and M. L. Tushman, "Dynamic capabilities at IBM: Driving strategy into action," California Management Review, 2007. 49(4).

[29] D. M. Hartmann, H. Brentel and H. Rohn, "Lern- und Innovationsfähigkeit von Unternehmen und Organisationen: Kriterien und Indikatoren," Wuppertal Papers, 2006. p. 156. https://www.econstor.eu/dspace/bitstream/10419/29716/1/511648 723.pdf

[30] G. Lembke, Die Lernende Organisation als Grundlage einer entwicklungsfähigen Unternehmung, 2001. http://www.learnact.de/literatur/GeraldLembke.pdf

[31] M. Gibbert, W. Ruigrok and B. Wicki, "What Passes as a Rigerous Case Study?" Strategic Management Journal, 2008. 29(13): p. 1465-1474. http://dx.doi.org/10.1002/smj.722

[32] R. K. Yin, Case Study Research. Design and Methods, Los Angeles, London, New Delhi, Singapore, Washington DC: SAGE, 2009 .
[33] M. Gibbert and W. Ruigrok, "The 'what' and 'how' of case study rigor. Three strategies based on published research," Organizational Research Methods, 2010. 13(4): p. 710-737. http://dx.doi.org/10.1177/1094428109351319

[34] U. Flick, E. Kardorff and I. Steinke, Qualitative Sozialforschung. Ein Handbuch, 6th ed. Hamburg: Rowohlt, 2008.

[35] U. Flick, Qualitative Sozialforschung. Eine Einführung, 2nd ed. Hamburg: Rowohlt, 2009.

[36] D. Schuchmann and S. Seufert, "Managing Organisational Learning for Continuous Innovation: An Empirical Examination in the Banking Sector," unpublished.

[37] S. Seufert, "Organisationslernen: die ,Organisation des Informellen " als treibender Motor?" in Organisationslernen im 21. Jahrhundert. Festschrift für Harald Geißler, C. Heidsiek, Ed. Frankfurt am Main: Peter Lang, 2010, p. 124-136.

[38] J. Waltert, Elektronische Kommunikationsforen als Element des Wissensmanagements. Eine Fallstudie bei genossenschaftlichen Filialbanken, Dissertation, Berlin: dissertation.de, 2002.

[39] A. Back, O. Bendel and D. Stoller-Schai, Dialogplattform Knowledge Management der Deutschen Bank $A G$, Arbeitsbericht, St.Gallen: Institut für Wirtschaftsinformatik, 2000.

\section{AUTHORS}

D. Schuchmann, Research Associate at the Insitute for Business Education and Educational Management at the University of St.Gallen, Dufourstrasse 40a, 9000 St.Gallen, Switzerland (daniela.schuchmann@unisg.ch).

S. Seufert, Professor for Business Education and Educational Management at the University of St.Gallen, Director of the Institute of Business Education and Educational Management at the University of St.Gallen, Dufourstrasse 40a, 9000 St.Gallen, Switzerland (sabine.seufert@unisg.ch).

Submitted 01 February 2015. Published as resubmitted by the authors 10 March 2015 